\title{
PARTICIPAÇÃO DE GRADUADOS EM ENGENHARIA NA ANPG - UMA ANÁLISE HISTÓRICA
}

DOI: 10.37702/2175-957X.COBENGE.2021.3644

Marcos Johari Provezani Silva - joharipro@gmail.com

UNITAU

RUA JOSEPHINA GONÇALVES DE ABREU, 106106

35681-045 - Itaúna - MG

Resumo: A Associação Nacional de Pós Graduandos e Pós Graduandas - ANPG - é a entidade representativa dos estudantes de pós graduação brasileiros. Tem papel importante nos debates nacionais de Ciência, Tecnologia e Inovação e reivindica direitos para os pós graduandos. Este estudo visa compreender a participação de engenheiros na diretoria da ANPG entre 2004 e 2021. Foi realizada uma análise documental para identificar informações relevantes e em seguida foi realizada uma análise quantitativa dos dados obtidos, utilizando um software de Business Inteligence. Os dados mostram que há baixa participação de engenheiros na associação. No período analisado apenas 4,23\% dos diretores eram graduados em engenharia. Os dados também revelaram que a maior parte dos diretores são mestrando residentes em São Paulo ou Minas Gerais. Mas, ao contrário do esperado, estes se encontram majoritariamente no interior e não na capital. Com as devidas ressalvas, observou-se que não houve participação de pessoas graduadas em engenharia do gênero feminino.

Palavras-chave: ANPG, movimento estudantil, movimento de pós graduação, pós graduação 


\section{(C) COBENGE \\ 28 a 30 de SETEMBRO \\ PARTICIPAÇÃO DE GRADUADOS EM ENGENHARIA NA ANPG - UMA ANÁLISE HISTÓRICA}

\section{INTRODUÇÃO}

Os estudantes de pós graduação do Brasil são representando nacionalmente pela Associação Nacional de Pós Graduandos - ANPG - e localmente pelas APGs - Associação de Pós Graduandos. A ANPG é a entidade representativa tanto de estudantes de lato sensu quanto de stricto sensu, sendo a sua diretoria eleita em congresso. Seguindo os regimentos específicos, todos programas de pós graduação podem realizar processos eleitorais e enviar delegados e delegadas para o Congresso Nacional de Pós Graduandos no qual é eleita a gestão da ANPG, entre outros objetivos. Percebe-se que a participação em entidades como a ANPG pode promover diversos benefícios para a coletividade e também para os indivíduos.

Este estudo tem como objetivo levantar informações sobre a participação de graduados em engenharia na diretoria da ANPG. Também visa avaliar o perfil destes diretores a partir dos elementos levantados. Para tal foi realizada a consulta em atas e documentos disponibilizados pela ANPG, que em seguida foram tabulados e analisados com uma ferramenta de Business Intelligence.

\section{REVISÃO DE LITERATURA}

A ANPG é uma entidade representativa brasileira com sede em São Paulo - SP. O Art. $2^{\circ}$ do seu estatuto estabelece que "a ANPG é a entidade máxima que tem por finalidade representar os (as) pós-graduandos (as) matriculados (as) nas modalidades lato sensu e stricto sensu" nas diversas instituições públicas ou privadas que ofertam estes cursos no país. A ANPG possui diversos objetivos como congregar e reunir os pós graduandos defender interesses de sua categoria, realizar eventos científicos e culturais, entre outros (ANPG, 2018).

Além da diretoria, o estatuto da ANPG define outras instâncias de deliberação da entidade, sendo a instância máxima o Congresso Nacional de Pós Graduandos - o CNPG. O CNPG tem diversos objetivos, entre os quais eleger a nova diretoria da entidade, para o período subsequente, alterar o estatuto e discutir e votar teses, moções e propostas. (ANPG, 2018).

Analisando o movimento estudantil em uma escola de engenharia, Machado (2013) apresenta que há congruência entre o exercício da profissão e a intervenção social e também entre formação profissional e projeto de país. Ademais, o autor apresenta que os estudantes transformam as relações existentes nas estruturas sociais a partir do contato com outros sujeitos na sociedade.

O ensino de engenharia passa por alguns desafios para os quais o movimento estudantil pode contribuir. Os cursos de engenharia não devem ser apenas um treinamento para as empresas (LAUDARES, 2009) mas fornecer uma compreensão global para a atuação do profissional na sociedade, de forma a transformá-la. Somando-se à esse conceito, existe uma relação entre ciência e democracia. A produção de ciência, tecnologia 
e inovação pode auxiliar a promover a soberania nacional e também o setor produtivo, devendo fazer parte do projeto de nação (ANPG et al., 2011). Por fim, a educação para a democracia demanda conhecimentos da vida social e política, formação ética, formação para a vida pública e valores democráticos, conforme apresentado por Benevides (2006).

A pós graduação brasileira se divide em lato sensu e stricto sensu. A lei brasileira define a pós graduação lato sensu são programas de especialização, inclusive MBA's, com duração mínima de $360 \mathrm{~h}$ e a pós graduação stricto sensu é composta por programas de mestrado e doutorado (BRASIL, 1996). Também é definido que as instituições de ensino tem autonomia para abrir cursos lato sensu e certificar seus alunos, tendo menos exigências para promover maior dinamicidade. Assim, o Ministério da Educação realiza o censo apenas para cursos stricto sensu. Portanto não é divulgado a quantidade de estudantes ou os cursos existentes de lato sensu.

A Coordenação de Aperfeiçoamento do Pessoal de Nível Superior - CAPES organiza os cursos de nível superior em oito grandes áreas do conhecimento. As áreas são: 1. Ciências Exatas e da Terra, 2. Ciências Biológicas, 3. Engenharias, 4. Ciências da Saúde, 5. Ciências Agrárias, 6. Ciências Sociais Aplicadas, 7 Ciências Humanas e 8. Linguística, Letras e Artes (GEOCAPES, 2021).

O GEOCAPES é um sistema de informações georreferenciadas da CAPES, no qual são disponibilizadas diversas informações sobre a pós graduação stricto sensu no país. Analisando os dados do GEOCAPES (2021) percebe-se que os três estados com maior volume de estudantes de stricto sensu são respectivamente São Paulo, Minas Gerais e Rio de Janeiro.

Utilizando o dado mais recente disponibilizado no sistema, têm-se que em 2019 o país possuía 292.766 estudantes de pós graduação stricto sensu. Os programas de engenharia contavam com 34.087 estudantes, representando 11,64\% do total (GEOCAPES 2021). A distribuição de discentes dos cursos de pós graduação stricto sensu por área de conhecimento são apresentadas na figura 1:

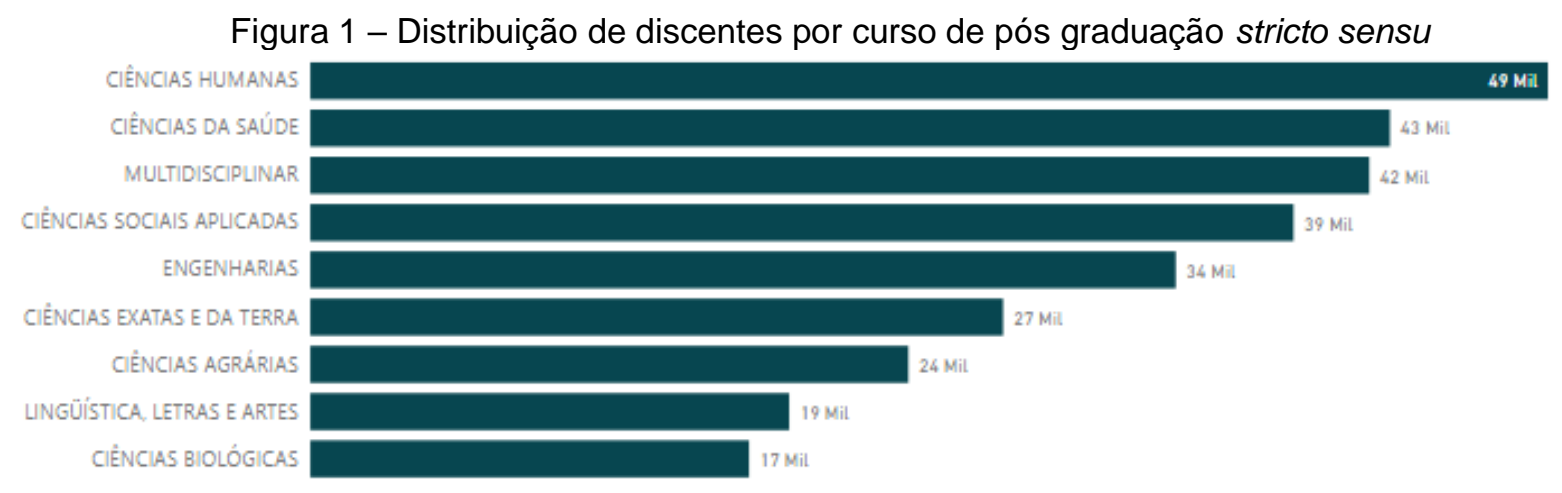

Fonte: GEOCAPES, 2021

\section{METODOLOGIA}

A metodologia de pesquisa se baseia em uma análise documental e em seguida foi realizada uma análise quantitativa dos dados obtidos. Inicialmente foi realizada uma revisão de literatura a ANPG, educação em engenharia e o perfil da pós graduação no Brasil. Também foi pesquisada a existência de outros artigos ou textos que haviam realizado esse levantamento, não tendo sido encontrados nenhum.

Para o levantamento do histórico de membros da diretoria da ANPG foi solicitado à entidade a disponibilização das atas. Foram disponibilizadas cópias digitais das atas de gestões que aconteceram entre 2004 e 2021. Em duas gestões foram utilizados outros 
documentos. A ata da gestão de 2008 não foi disponibilizada. Foi consultada nominata da diretoria disponível no documento "Anais da $2^{\text {a }}$ Mostra Científica da ANPG" (ANPG, 2008) para levantamento das informações. Para a gestão de 2020 à 2022 foi utilizada a nominata de diretores e diretoras, visto que a ata ainda não estava finalizada quando este artigo foi elaborado.

As informações da ata foram então tabuladas em uma planilha. De forma geral, as atas continham o nome, diretoria, universidade em que realizava a pós graduação e endereço; além de documentos pessoais e outras informações. Em seguida a planilha foi analisada utilizando a versão gratuita do software de Business Intelligence Power $\mathrm{BI} \circledast$, um programa utilizado para apresentação e análise de dados.

Para a graduação definiu-se que seria utilizada a informação disponibilizada na ata como profissão. Em algumas atas essa informação não estava disponível ou estava uma profissão "generalista" como "estudante", "mestrando" ou "professor". A instituição de ensino considerada no levantamento também é a disponibilizada em ata. A graduação das diretorias foi classificada em "Engenharias" e "Outras", em que esta última são todos outros cursos. Para classificar os cursos foi utilizada a grande área do conhecimento, disponibilizada no GEOCAPES (2021).

$\mathrm{O}$ estado e cidade de origem também é aquele disponibilizado em ata. Para as situações em que não havia sido informado em ata, considerou-se o endereço da instituição de ensino em que o pós graduando estava cursando. Para as informações que não constavam em ata foi realizada uma pesquisa pelo nome na base do Currículo Lattes. Quando houver mais de uma graduação informada, definiu-se que seria considerada a formação mais antiga exceto no caso de haver uma formação posterior em engenharia. Entretanto essa situação não ocorreu dentre os formados em engenharia. Para a instituição de ensino considerou-se aquela em que o período informado no Lattes correspondia ao período da gestão.

Dentre os currículos pesquisados, alguns tinham várias pessoas com mesmo nome. Neste caso foi verificado cada currículo isoladamente para procurar por evidências como o informe de participação na entidade, a participação em eventos da ANPG ou o período de pós graduação. Para as situações que não houvesse informações suficientes definiu-se o código ND de "Não Disponível".

Sobre a definição do gênero, cabe uma discussão mais aprofundada. O gênero é o papel social que a pessoa representa na sociedade, não estando atrelado à questão biológica. É um recorte importante em estudos deste tipo por avaliar as estruturas de poder (OLIVEIRA et al.,2020). Entretanto os documentos consultados não apresentam o gênero das pessoas diretoria. Assim, seguiu-se o realizado em alguns estudos que fizeram este recorte (OLIVEIRA et al., 2020; COSTA et al., 2019): buscou-se marcadores de gênero nos documentos consultados (atas, arquivos e currículos Lattes) e também pelo nome. Importante reforçar que se deve ter cautela com essa parte. Conforme ressaltado por Oliveira et al. (2020) essa abordagem não "significa aderir a uma perspectiva exclusivamente binária", mas ainda assim é um diagnóstico oportuno de ser feito.

\section{$4 \quad$ RESULTADOS}

Para o levantamento dos dados foram utilizados os dados disponibilizados pela entidade (ata e nominata) e o documento "Anais da $2^{\mathrm{a}}$ Mostra Científica da ANPG" (ANPG, 2008). Foram levantados dados de dez gestões, a partir de 2004. No Quadro 1 são apresentados o ano de início de cada gestão verificada e qual documento consultado para extrair as informações: 
Quadro 1: Ano de início da gestão e documento consultado

\begin{tabular}{|c|c|}
\hline Início & Documento \\
\hline 2004 & Ata \\
\hline 2005 & Ata \\
\hline 2006 & Ata \\
\hline 2008 & Anais \\
\hline 2010 & Ata \\
\hline 2012 & Ata \\
\hline 2014 & Ata \\
\hline 2016 & Ata \\
\hline 2018 & Ata \\
\hline 2020 & Nominata \\
\hline
\end{tabular}

Fonte: O autor

Para facilitar a compreensão, nos referenciaremos à cada gestão por seu ano de início. Exemplificando, ao se falar em Gestão 2018 referenciar-se-á à gestão que inicia em 2018 e finaliza em 2020. O estatuto atual define um prazo de 24 meses para a gestão, mas nas gestões 2004 e 2005 o período era menor.

Nas gestões analisadas foram eleitas 265 pessoas para as diretorias da entidade. Consultando as atas e a plataforma Lattes foi possível encontrar as informações de formação na graduação para 260 pessoas. Foram descartados desta análise duas diretorias para as quais não se tinham os dados necessários e três diretorias para as quais havia mais de um currículo lattes com o mesmo nome e sem ter como identificar qual era o correto. Foi possível avaliar a graduação de $98,1 \%$ da base disponibilizada. Não foram encontrados dados referentes à Diretoria Vice Norte em 2004, às Diretorias de Comunicação e Vice Sul em 2006, à Diretoria de Comunicação em 2008 e à Diretoria Vice Norte em 2012. Nas análises a seguir serão consideradas as 260 diretorias para as quais se obteve os dados.

A quantidade de diretorias em cada gestão variou ao longo dos anos. Devido à ampliação da atuação da entidade foram sendo criadas ou alteradas diretorias em alguns congressos. A Figura 2 apresenta a quantidade de diretorias por gestão.

Figura 2: Quantidade de diretorias da ANPG por gestão

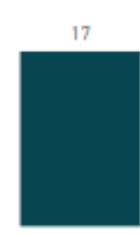

2004

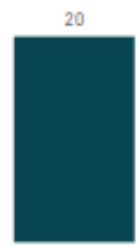

2005

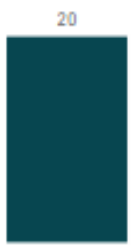

2006

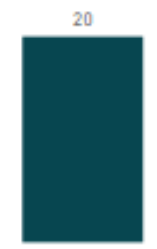

2008

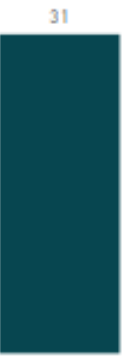

2010

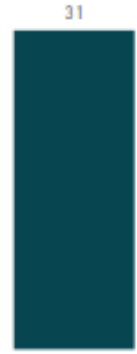

2012

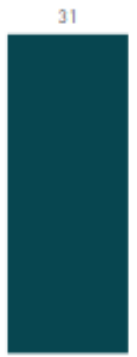

2014

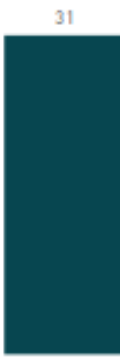

2016

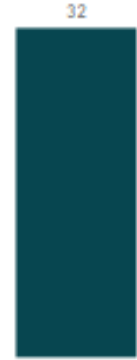

2018

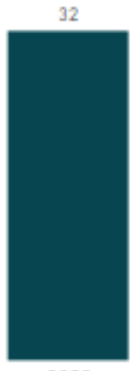

2020

Fonte: O autor

$\mathrm{Na}$ Figura 3 são apresentadas as gestões que tiveram diretores graduados em engenharia e a respectiva volumetria: 


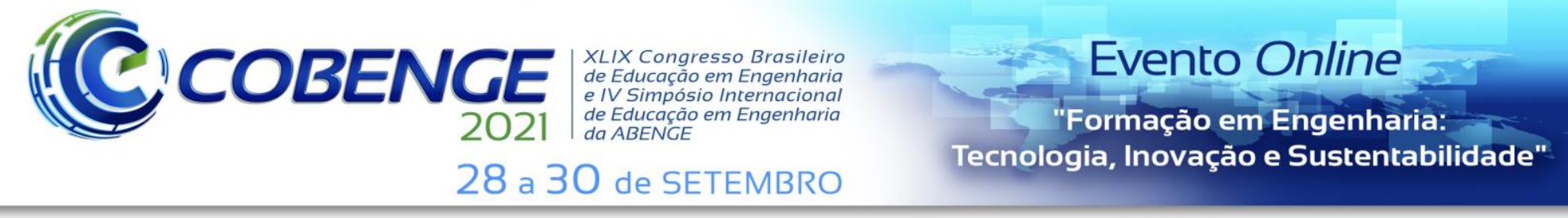

Figura 3: Volumetria de engenheiros por gestão

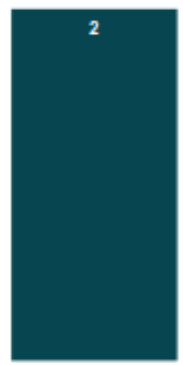

2004

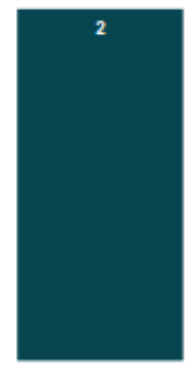

2005

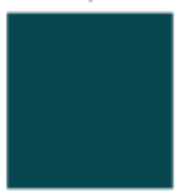

2006

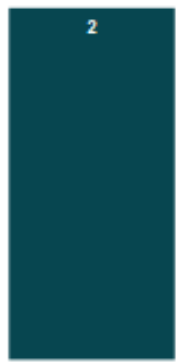

2008

Gestão

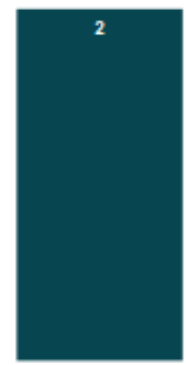

2014

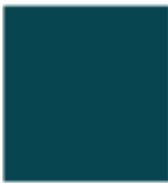

2018

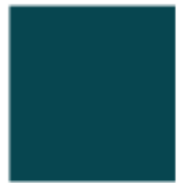

2020

Fonte: O autor

Por fim, foi construído um gráfico de barras $100 \%$. Foram utilizadas duas categorias: Engenharias e Outras. A categoria Engenharias engloba os diretores graduados em cursos de engenharia enquanto a categoria Outras engloba todos outros diretores. Esse tipo de gráfico é utilizado para avaliar a porcentagem das categorias avaliadas em relação ao todo. No caso específico, foi construído em cima de uma série temporal. Os dados obtidos são apresentados na Figura 4:

Figura 4: Proporção de engenheiros em cada gestão

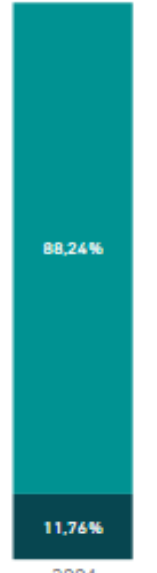

2004

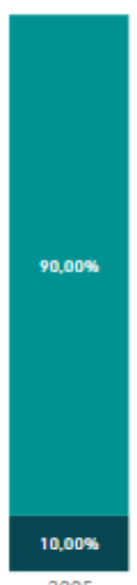

2005

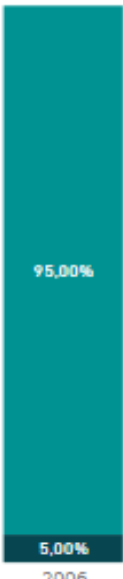

2006

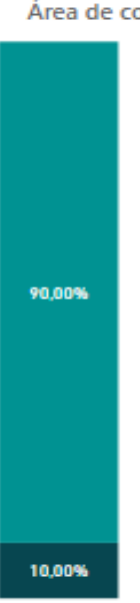

2008

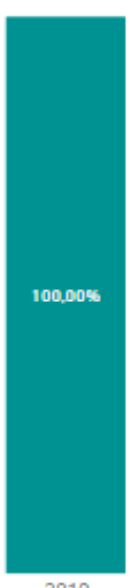

2010

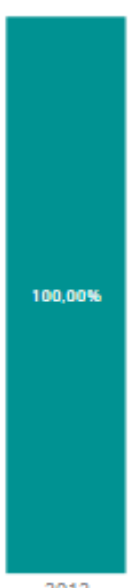

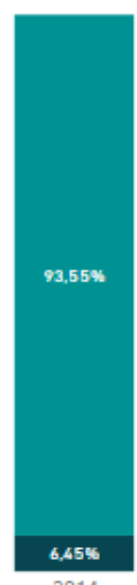

2014

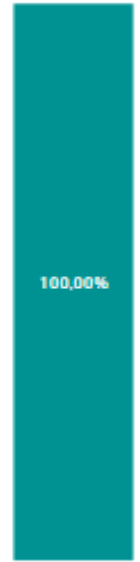

2016

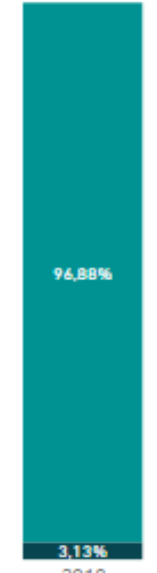

2018

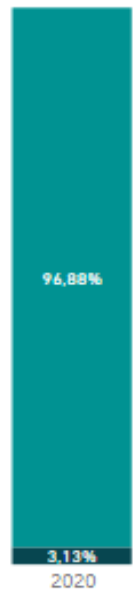

Fonte: O autor

No período analisado foram eleitos onze diretores graduados em engenharia. Em três gestões não foi identificada nenhuma diretoria que fora ocupada pela segmentação realizada. A seguir foi elaborada a análise de estado do diretor. Foi considerado o estado de residência declarado em ata. Quando essa informação não estava disponível, foi considerado o estado em que se encontra a universidade que o diretor estava matriculado. Os dados foram organizados por gestão e apresentados na Figura 5: 
Figura 5: Estado de residência dos diretores

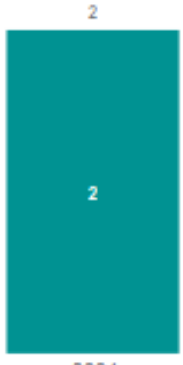

2004

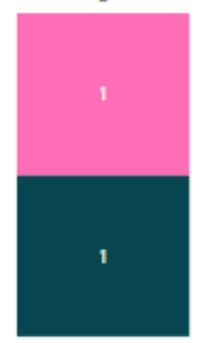

2005

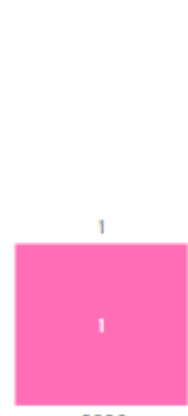

2006

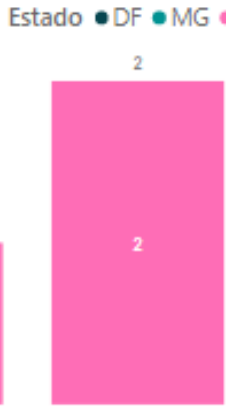

2008

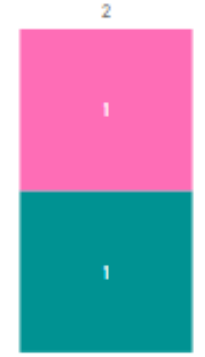

2014

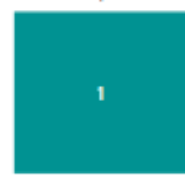

2018

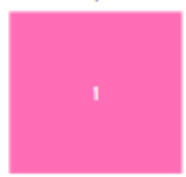

2020

Fonte: O autor

Em seguida procedeu-se a análise das diretorias paras as quais o segmento estudado foi eleito. A Quadro 02 apresenta quais diretorias foram ocupadas no período analisado e a quantidade de ocorrências:

Quadro 02: Diretorias da ANPG cujo diretor é engenheiro

\begin{tabular}{|c|c|}
\hline Diretoria & Qntd de ocorrências \\
\hline $2^{\circ}$ Relações Institucionais & 1 \\
\hline Ciência e Tecnologia & 1 \\
\hline Cultura e Eventos & 1 \\
\hline Políticas de Juventude & 1 \\
\hline Pós graduação Lato Sensu & 1 \\
\hline Presidência & 1 \\
\hline Vice Centro-oeste & 1 \\
\hline Vice São Paulo & 2 \\
\hline Vice Sudeste & 2 \\
\hline
\end{tabular}

Fonte: $\mathrm{O}$ autor

No período avaliado foram onze diretorias ocupadas por engenheiros. Avaliando-se as ocorrências únicas de nome percebeu-se que três pessoas haviam sido eleitas para mais de uma gestão. Ou seja, no período avaliado foram oito pessoas graduadas em engenharia que participaram da entidade

Foi identificado em qual nível o estudante estava realizando sua pós graduação enquanto estava na diretoria da entidade. Se era Lato Sensu ou Stricto Sensu. Para os estudantes de Stricto Sensu, foi realizada a segmentação entre Mestrado e Doutorado. Para uma ocorrência não foi possível determinar a instituição onde realizou a pós graduação e qual nível estava, sendo apresentado como "Não Disponível" - "ND" - no gráfico. Os dados obtidos são apresentados na Figura 6:

Figura 6: Nível de pós graduação

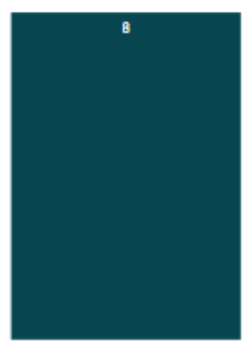

Mestrado

Fonte: O autor 
Considerando a instituição em que o diretor realizou a pós graduação enquanto estava na gestão, obteve-se a segmentação por status jurídico da instituição, que é apresentada no Quadro 3:

Quadro 3: Status jurídico da instituição

\begin{tabular}{|c|c|}
\hline Status Jurídico & Ocorrências \\
\hline Pública Federal & 5 \\
\hline Pública Estadual & 3 \\
\hline Pública Municipal & 1 \\
\hline Particular & 1 \\
\hline Não Disponível & 1 \\
\hline
\end{tabular}

Fonte: $\mathrm{O}$ autor

\section{$5 \quad$ DISCUSSÃO}

A participação no movimento de pós graduandos e consequentemente no movimento estudantil tem diversos benefícios. Auxilia na formação política e social das pessoas além de contribuir na educação para a democracia. Promove melhor compreensão das políticas públicas de Ciência, Tecnologia e Inovação, de educação e diversos outros temas. Mas não só promove a compreensão como propicia formas de apresentar propostas e construir de fato essas políticas, transformando a sociedade.

A participação também tem benefícios positivos para a formação pessoal e profissional do participante. Percebe-se a melhoria de diversas habilidades desejáveis como a comunicação e oratória, a capacidade de análise crítica e complexa, habilidades de gestão, de resolução de conflitos entre diversas outras.

Mesmo com os diversos benefícios coletivos e individuais que a participação na ANPG pode propiciar, o primeiro ponto observado é a baixa ou nula participação de graduados em engenharia na diretoria da ANPG. Em três gestões não houve a participação e as gestões que tiveram mais engenheiros contaram com apenas duas diretorias. As onze diretorias representam $4,23 \%$ das diretorias avaliadas enquanto que estudantes de stricto sensu em cursos engenharia representam 11,64\% do total. A baixa participação, também reflete na composição da na diretoria executiva e na mesa diretora da entidade. Ainda que ocorra uma eleição da diretoria, é importante buscar compreender as razões que levam à essa baixa participação.

Outro reflexo é na estrutura da ANPG. Ela é organizada em Diretorias Plenas e Diretoria Executiva. A diretoria plena tem papel de representação política e atuação específica de sua diretoria e a diretoria executiva acumula o papel da plena com a de execução das atividades inerentes à entidade em si além de servir como um fórum mais restrito em que são tomadas decisões mais rapidamente. Das onze diretorias ocupadas por engenheiros, apenas duas eram da diretoria executiva: a presidência e a Diretoria de Ciência e Tecnologia. Ressalta-se que a Diretoria de Juventude em 2018 e a $2^{\text {a }}$ Diretoria de Relações Institucionais em 2020 foram consideradas plenas com status de executiva. Ou seja, tinham espaço na tomada de decisões do fórum executivo.

Uma função importante nos eventos da ANPG é a mesa diretora, composta pela Presidência, Vice Presidência e Secretaria. Tradicionalmente são essas pastas que dirigem os eventos e tem a possibilidade de intervir na administração das plenárias e atividades. No levantamento realizado, apenas em 2008 a mesa diretora teve a participação de alguém formado em engenharia, no caso o presidente da entidade.

Outro ponto de destaque é a concentração de residência dos diretores no Sudeste. O levantamento revelou que seis diretores residiam em São Paulo, quatro em Minas Gerais e um no Distrito Federal. Ainda que São Paulo e Minas Gerais sejam dois dos três estados 
com maior volume de matrículas, não justifica a concentração. Também não é perceptível uma possível mudança de estado devido à participação na entidade, visto não ter nenhuma residência declarada na cidade de São Paulo, sede da ANPG.

Um possível ponto a ser considerado em estudos futuros é a possibilidade de, nestes estados, o movimento de pós graduandos ser mais organizado, com mais membros e formando mais pessoas com disponibilidade e capacidade de compor a diretoria da entidade. Mas é necessário aprofundar mais nesse assunto.

Ao iniciar este estudo acreditava-se que a maioria dos diretores residiram em capitais, por serem os centros políticos dos estados. Mas a análise documental revelou que a maioria das diretorias declararam residência em cidades do interior. Foram nove ocorrências no interior, uma Belo Horizonte e outra Brasília. Dois dos três diretores que participaram de mais de uma gestão mudaram a residência entre o início de uma gestão e outra.

Ainda que o cenário tenha se modificado nos últimos anos, os cursos de engenharia são compostos majoritariamente por homens. Para identificar o possível gênero das pessoas, buscou-se por possíveis indicadores, seguindo a metodologia utilizada em outros trabalhos (COSTA et al., 2019; OLIVEIRA et al., 2020). Em todas ocorrências houve indicadores de gênero nas atas ou Lattes, como por exemplo "engenheiro" ou "consultor", levando a crer que $100 \%$ das diretorias foram ocupadas por pessoas do gênero masculino e não houve participação de pessoas do gênero feminino. Esse método de identificação deve ser considerado com as devidas ressalvas concernentes ao debate de gênero. Ainda assim é um diagnóstico oportuno, conforme avaliado por Oliveira et al. (2020).

Os dados obtidos não apresentam concentrações significativas em alguma diretoria específica. Também não apresenta discrepância significativa na proporção de estudantes, considerando o recorte de status jurídico da instituição. Um destaque deve ser dado à participação de estudantes de mestrado, representando $80 \%$ dos dados encontrados.

\section{CONSIDERAÇÕES FINAIS}

A participação nas organizações do movimento estudantil promove diversos benefícios para a coletividade e também para o indivíduo. Ainda assim, confirma-se que há baixa participação de pós graduandos formados em engenharia na ANPG. É importante promover reflexões sobre os motivos que levam à essa baixa participação de engenheiros e engenheiras, de forma a ampliar a representatividade deste segmento.

Considerando a segmentação da diretoria por graduados em engenharia, foram revelados dados interessantes. Foram eleitos apenas onze engenheiros para as gestões da ANPG entre 2004 e 2021, de um total de 265 diretorias eleitas. No período analisado identificou-se uma concentração de residência dos diretores nos estados de São Paulo e Minas Gerais, apenas um residia em outro local (Brasília, DF).

Esperava-se que a maioria dos diretores residissem na capital de seus estados mas ao contrário do esperado, nove dos onze diretores residiam no interior do estado. Com as devidas ressalvas do método de identificação, percebeu-se que todos diretores no período analisado eram do gênero masculino. Por fim, observou-se que a maior parte eram estudantes de mestrado, provocando uma sub-representação de outros níveis, em especial o lato sensu.

Por fim, são sugeridas três possibilidades de estudos futuros. O primeiro é aprofundar o conhecimento sobre a participação de engenheiros no movimento de pós graduandos, ampliando o estudo para as Associações de Pós Graduandos (APGs Entidades representativas locais). A segunda sugestão é a realização de outras avaliações da composição das gestões da ANPG, com outras segmentações que não a de 
engenharias. Por fim, sugere-se realizar um estudo semelhante para o movimento estudantil de graduação e a União Nacional dos Estudante, UNE.

\section{Agradecimentos}

Agradeço à Associação Nacional de Pós Graduandos e Pós Graduandas por disponibilizar os documentos necessários para a realização desta pesquisa.

\section{REFERÊNCIAS}

Associação Nacional de Pós Graduandos - ANPG. Anais da 2ª mostra científica da ANPG. Campinas: ANPG, 2008. 70 p.

. Estatuto da ANPG. Disponível em: www.anpg.org.br . Acesso em 10 abr. 2021.

ANPG et al. Os pós-graduandos e a agenda estratégica em ciência, tecnologia e inovação. Parc. Estrat., Brasília, v. 16, n. 32, p. 93-107, jul. 2011.

BENEVIDES, Maria Victoria de Mesquita. Educação para a democracia. Lua Nova: Revista de Cultura e Política, [S.L.], n. 38, p. 223-237, dez. 1996. FapUNIFESP (SciELO). http://dx.doi.org/10.1590/s0102-64451996000200011.

BRASIL. Lei no 9394, de 20 de dezembro de 1996. Estabelece As Diretrizes e Bases da Educação Nacional. Brasília, 20 dez. 1996.

COSTA, Lilian et al. Diversidade de Gênero nos Conselhos Administrativos e sua Relação com Desempenho e Risco Financeiro nas Empresas Familiares. Revista de Administração Contemporânea, [S.L.], v. 23, n. 6, p. 721-738, nov. 2019. FapUNIFESP (SciELO). http://dx.doi.org/10.1590/1982-7849rac2019180327.

GEOCAPES. Sistema de dados estatísticos da CAPES. Disponível em: https://geocapes.capes.gov.br/geocapes/. Acesso em: 25 abr. 2021.

LAUDARES, João Bosco et al. O ensino de engenharia e a formação do engenheiro: contribuição do programa de mestrado em tecnologia do CEFET-MG - educação tecnológica. Educação \& Tecnologia, Belo Horizonte, v. 14, n. 1, p. 60-67, abr. 2009.

MACHADO, Otávio Luiz. Movimentos Estudantis, Formação Profissional e Construção de um Projeto de País: a experiência da engenharia na UFPE (1958-1975). 2. ed. Frutal: Prospectiva, 2013. $263 \mathrm{p}$.

OLIVEIRA, Jussara Ribeiro de et al. Participação feminina na pesquisa sobre tecnologia da informação no Brasil: grupos de pesquisa e produção científica de teses e dissertações*. Cadernos Pagu, [S.L.], n. 58, p. 1-51, 2020. FapUNIFESP (SciELO). http://dx.doi.org/10.1590/18094449202000580004

\section{PARTICIPATION OF GRADUATES IN ENGINEERING AT ANPG - A HISTORICAL ANALYSIS}

Abstract: The National Association of Graduate Students - ANPG - is the representative entity of Brazilian graduate students. It plays an important role in national debates on Science, Technology and Innovation and claims rights for graduate students. This study aims to understand the participation of engineers on the board of ANPG between 2004 and 2021. A document analysis was carried out to identify relevant information and then a quantitative analysis of the data obtained was made, using Business Intelligence software. 
The data show that there is a low participation of engineers in the association. In the analyzed period only $4.23 \%$ of the directors were graduated in engineering. The data also revealed that most of the directors are master's students residing in São Paulo or Minas Gerais. But, contrary to expectations, they are mostly located in the interior and not in the capital. With due reservations, it was observed that there was no participation of female gender engineering graduates....

Keywords: ANPG, Student Activism, Graduate Activism, Graduate 